\title{
EXCITATORY AND DEPRESSANT EFFECTS OF DIELDRIN AND ALDRIN-TRANSDIOL IN THE SPINAL CORD OF THE TOAD (XENOPUS LAEVIS)
}

\author{
LOUIS M.A. AKKERMANS, JOEP VAN DEN BERCKEN and MARJAN VERSLUIJS-HELDER \\ Institute of Veterinary Pharmacology and Toxicology, \\ University of Utrecht, Biltstraat 172, Utrecht, The Netherlands
}

Received 2 December 1974, revised MS received 1 April 1975, accepted 2 June 1975

L.M.A. AKKERMANS, J. VAN DEN BERCKEN and M. VERSLUIJS-HELDER, Excitatory and depressant effects of dieldrin and aldrin-transdiol in the spinal cord of the toad (Xenopus laevis), European J. Pharmacol. 34 (1975) 133-142.

An investigation was made into the action of the insecticide dieldrin and one of its metabolites, aldrin-transdiol, on the isolated spinal cord of the toad, Xenopus laevis. Conventional electrophysiological techniques w'sre used for stimulating and recording of dorsal and ventral spinal roots. An augmentation of polysynaptic reflex activity along with a marked reduction of orthodromic postsynaptic inhibition could be demonstrated in preparations isolated from dieldrin-poisoned animals. However, application of dieldrin to the isolated spinal cord failed to produce any significant effect. Application of aldrin-transdiol, on the other hand, caused a potentiation of spinal reflex activity and an increase in spontaneous activity of ventral and dorsal roots. Aldrin-transdiol also produced a marked reduction of spinal inhibitory mechanisms. The excitatory effects of aldrin-transdiol were followed by a strong depressant action on spinal excitability.

Isolated spinal cord

Postsynaptic inhibition
Spinal root potentials

Presynaptic inhibition
Dieldrin Aldrin-transdiol

\section{Introduction}

We have recently reported (Akkermans et al., 1974a,b) that aldrin-transdiol, one of the metabolites of the insecticide dieldrin, strongly affected synaptic transmission in the frog motor end-plate. In sharp contrast with this, dieldrin itself and two other metabolites remained without effect. Aldrin-transdiol initially caused a marked potentiation of both spontaneous and evoked transmitter release, which was followed later by a complete blockade of transmission. Aldrin-transdiol has been shown also to suppress conduction in the giant axon of the squid while dieldrin itself again remained without effect (Van den Bercken and Narahashi, 1974). These observations provide strong evidence for regarding aldrin-transdiol as one of the active forms of dieldrin, as was originally suggested by Narahashi (1971) and Wang et al. (1971).

It is clear, however, that the primary site of action of dieldrin - or aldrin-transdiol - is not located in the neuromuscular junction or in the peripheral nerve membrane, but somewhere in the central nervous system (Gowdey et al., 1954; Gowdey and Stavraky, 1955). Gowdey et al. (1952) showed that aldrin augmented the reflex activity of the spinal cord and the excitability of spinal centres to acetylcholine and pentylenetetrazol (Metrazol). Aldrin is rapidly converted to dieldrin in the animal body and the effects of aldrin will therefore also hold good for dieldrin (Giannotti et al., 1956; Bann et al., 1965; Brooks, 1960). That dieldrin increases sensitivity to pentylene- 
tetrazol was confirmed also by Natoff and Reiff (1967). Preliminary experiments (Van den Bercken, unpublished) have shown that dieldrin, although after a long latency, induces hyperexcitability in spinal toads. These results prompted a further investigation of the effects of dieldrin and aldrin-transdiol in the isolated spinal cord.

\section{Materials and methods}

All experiments were performed on the isolated spinal cord of the clawed toad, Xenopus laevis. Prechilled toads were anesthesized by having $100 \mathrm{mg} / \mathrm{kg}$ tricaine methanesulfonate (MS-222 Sandoz) injected into the dorsal lymph sac. In previous control experiments this dose was found to allow complete recovery of intact animals within about $30 \mathrm{~min}$ (cf. Hobson and Townsed, 1964). After immobilization of the animal the spinal cord was transected at the level of the 4 th ventricle and the spinal canal was opened by dorsal laminectomy, mainly as described by Holemans et al. (1967), with the aid of an 'air-rotor' dental drill. Earlier experiments, in which a simple motor-driven drill was used, were unsuccessful, probably as a result of mechanical trauma (Holemans and Meij, 1968). On reappearance of the reflex activity, the spinal cord with roots IX and X was removed from the animal. The time elapsed between injection of MS-222 and start of the experiment was at least $90 \mathrm{~min}$ to ensure complete recovery from anesthesia. In some experiments the cord was left intact, while in others it was cut sagittally. No difference in response could be established between these preparations.

The experiments were carried out at a temperature of $10 \pm 2{ }^{\circ} \mathrm{C}$ in a double-walled, plexiglass bath with a volume of about $10 \mathrm{ml}$. The spinal cord was placed on its side in a central groove which was continuously perfused with oxygenated Ringer solution, at a rate of about $2 \mathrm{ml} / \mathrm{min}$. The ipsilateral IXth and Xth dorsal (DR) and ventral roots (VR) were pulled through silicone jelly-sealed slits on either side of the central groove, mounted on a pair of silver wire electrodes in separate side pools and covered with paraffin oil to prevent desicca- tion. Supramaximal, rectangular stimuli of 0.1 msec in duration were delivered through a photoelectric isolation unit. For recording purposes, one electrode was connected to ground and root potentials were measured through single-ended, AC-coupled, preamplifiers (time constant $3 \mathrm{sec}$ ). An additional silver wire electrode was used to ground the central groove. Root potentials were displayed on an oscilloscope and photographed. In most experiments a transient recorder (Biomation 802) was used as a storage device. Stable records could be obtained from control preparations for more than $5 \mathrm{hr}$. After this the amplitude of the root potentials gradually diminished until eventually, after more than $7 \mathrm{hr}$, all electrical activity disappeared.

The Ringer solution used had the following composition (in $\mathrm{mM}$ ): $\mathrm{NaCl} 100, \mathrm{KCl} 2.5$, $\mathrm{Na}_{2} \mathrm{HPO}_{4}$ 2.5, $\mathrm{NaH}_{2} \mathrm{PO}_{4} \quad 0.45, \mathrm{NaHCO}_{3}$ 12, $\mathrm{CaCl}_{2} 1.9$ and glucose 2.8; final $\mathrm{pH} 7.3 \pm 0.1$. During the experiments the Ringer solution in the supply bottle was continuously aerated with a mixture of $95 \% \mathrm{O}_{2}-5 \% \mathrm{CO}_{2}$. Dieldrin (99.4\% HEOD, 1,2,3,4,10,10-hexachloro-6,7epoxy-1,4,4a, 5,6,7,8,8a-octahydro-endo-1,4exo-5,8-dimethanonaphthalene) or aldrintransdiol $(99 \% \quad 1,2,3,4,10,10$-hexachloro-6,7trans-dihydroxy -1,4-endo-5,8-exo-dimethano$1,4,4 \mathrm{a}, 5,6,7,8,8 \mathrm{a}$-octahydronaphthalene) was added to the Ringer solution while ethanol was used as a solvent.

In a first series of experiments animals were treated with dieldrin in vivo by having 35 $\mathrm{mg} / \mathrm{kg}$ (2.5\% ethanol in Ringer solution) injected into the dorsal lymph sac. As soon as symptoms of poisoning, i.e., hyperexcitability and convulsions, began to show the animal was quickly put on ice, anesthesized with MS-222 and the spinal cord was isolated. The time between injection of dieldrin and development of symptoms of poisoning varied from 2 to $8 \mathrm{hr}$ in different experiments. When drugs were applied to the isolated spinal cord in vitro the final concentration of ethanol, which was less than $0.05 \%$, was found to have no effects in separate control experiments (cf. Davidoff, 1973). 


\section{Results}

\subsection{Effects of dieldrin}

\subsubsection{Ventral and dorsal root potentials}

Fig. $1 \mathrm{~A}$ shows a recording of a typical ventral root potential elicited by supramaximal stimulation of the dorsal root of the same segment (DR-VRP) in a control preparation. The DRVRP consisted of a highly synchronized spike potential, presumably monosynaptic (Holemans et al., 1966), followed by electrotonically conducted synaptic potentials with superimposed polysynaptic discharges. The occurrence of a synchronized reflex discharge in response to a single stimulus is at variance with earlier observations in the isolated spinal cord of Xenopus laevis by Holemans et al. (1966). In their study a second stimulus to the dorsal root was usually necessary to evoke a synchronized spike in the ventral root.

In most spinal cords isolated from dieldrintreated animals no alterations of the DR-VRP with respect to control could be observed. Effects in these in vivo experiments, if any, are questionable in view of the lack of control observations in the same preparations. In 4 out of 15 preparations, however, a striking increase was recorded in polysynaptic activity (fig. 1B), which was never seen in control experiments.

Dorsal root potentials result from presynaptic terminal depolarization, which spreads electrotonically along the dorsal root (Barron and Matthews, 1938). These potentials are considered to be the expression of presynaptic inhibition (Eccles, 1964; Grinnell, 1966; Holemans and Meij, 1968; Schmidt, 1971). In no case were any significant changes observed in dorsal root potentials elicited by stimulation of either the ventral root of the same segment (VR-DRP) or the adjacent dorsal root (DRDRP). Representative control recordings of the VR-DRP and DR-DRP are shown in figs. 7 and 9 .

\subsubsection{Facilitation and inhibition of the $D R$ - $V R P$}

Facilitation and inhibition of the DR-VRP

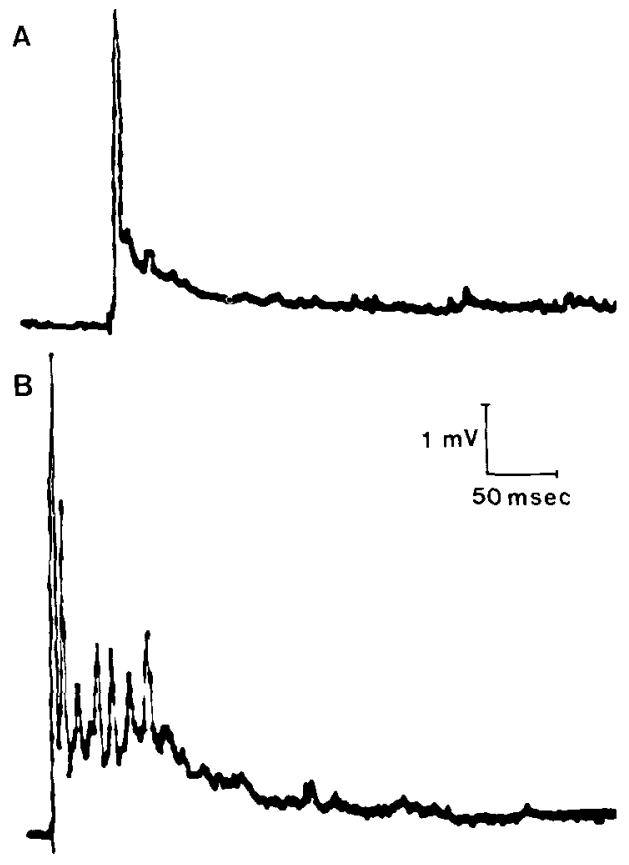

Fig. 1. Effects of dieldrin in vivo on DR-VRP. Typical DR-VRP in a control preparation (A) and in a spinal cord isolated from an animal treated with $35 \mathrm{mg} / \mathrm{kg}$ dieldrin in vivo (B). Note the increased polysynaptic activity.

were studied by applying two successive stimuli of equal strength to the same dorsal root, a conditioning and a test stimulus, separated by different time intervals. Fig. 2, upper tracing, shows a typical example of the DR-VRP upon two successive stimuli in a control preparation. At a stimulus interval of $15 \mathrm{msec}$ (fig. $2 \mathrm{~A}$ ) and $60 \mathrm{msec}$ (fig. 2C) the synchronized reflex discharge is greatly facilitated, whereas at an interval of $40 \mathrm{msec}$ (fig. 2B) the second response was almost completely blocked. This latter effect is thought to be the result of postsynaptic orthodromic inhibition (Holemans and Meij, 1968). The lower tracing of fig. 2 shows the 'paired' DR-VRP at the same stimulus intervals in a spinal cord isolated from a dieldrin-treated animal, Most obvious here is that at an interval of $40 \mathrm{msec}$ the test response became greatly facilitated instead of depressed, as was the case in the control experiments. This effect of dieldrin was studied in more detail by 

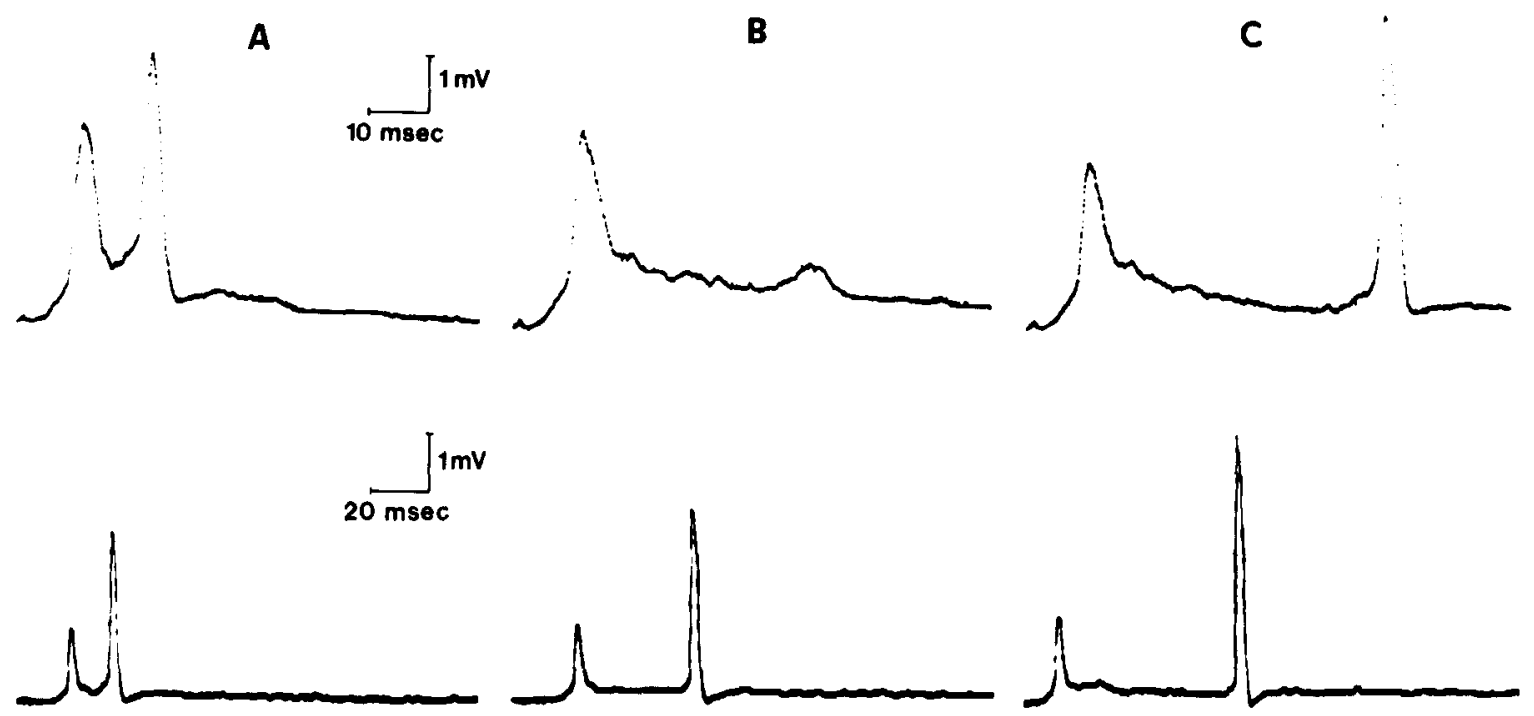

Fig. 2. Effects of dieldrin in vivo on orthodromic inhibition of the DR-VRP. DR-VRP's evoked by two successive stimuli to the same segment, separated by an interval of 15 (A), 40 (B) and $60 \mathrm{msec}$ (C) respectively in a control preparation (upper tracing) and in a spinal cord from an animal treated with $35 \mathrm{mg} / \mathrm{kg}$ dieldrin in vivo (lower tracing). Note the lack of inhibition at a stimulus interval of $40 \mathrm{msec}$ in the lower tracing.

varying the interval between the two stimuli from $5 \mathrm{msec}$ to $1 \mathrm{sec}$ and facilitation curves (Holemans et al., 1966) were constructed. Fig. 3 shows a typical facilitation curve of a control preparation and of a spinal cord isolated from a dieldrin-treated animal. Facilitation was expressed here as the ratio between the amplitudes of the conditioning response and the test response times $100 \%$. Peak amplitudes of the synchronized reflex discharges were measured. Although there were considerable differences in the characteristics and time course of the facilitation curves in the control experiments, they always showed two peaks with a period of depression in between. The second peak was always higher than the first ( $160 \pm 67$ and $287 \pm$ $53 \%$ respectively, mean \pm S.D., $n=6$ ). The facilitation curves of the spinal cords isolated from the dieldrin-treated animals showed a marked difference. Inhibition of the synchronized reflex discharge could no longer be detected and the facilitation curves had only one peak [291 $\pm 79 \%$; mean \pm S.D., $n=6$ ). The maximum facilitation of the DR-VRP after dieldrin poisoning in vivo did not differ significantly from the second facilitation peak in the control preparations ( $p>0.05$; Student's $t$ test). There was, however, one exception in which the facilitation in a dieldrin-treated preparation reached a maximum of $1450 \%$.

\subsubsection{Effects of dieldrin in vitro}

Application of dieldrin to the isolated spinal cord in vitro in concentrations of up to $5 \times$ $10^{-5} \mathrm{M}$ for more than $3 \mathrm{hr}$ caused no significant effect on DR-VRP, VR-DRP and DR-DRP, or on the facilitation or inhibition of the DRVRP. No higher concentrations of dieldrin were used, because the final concentration of ethanol (which was used as a solvent) had to remain less than $0.05 \%$, in order to avoid additional effects on the isolated spinal cord (cf. Davidoff, 1973).

\subsection{Effects of aldrin-transdiol}

Application of aldrin-transdiol to the isolated spinal cord in concentrations ranging from 1 to $5 \times 10^{-5} \mathrm{M}$ produced variable effects. In some experiments initial excitatory effects on spinal transmission were followed by a progressive depression, while in other experi- 


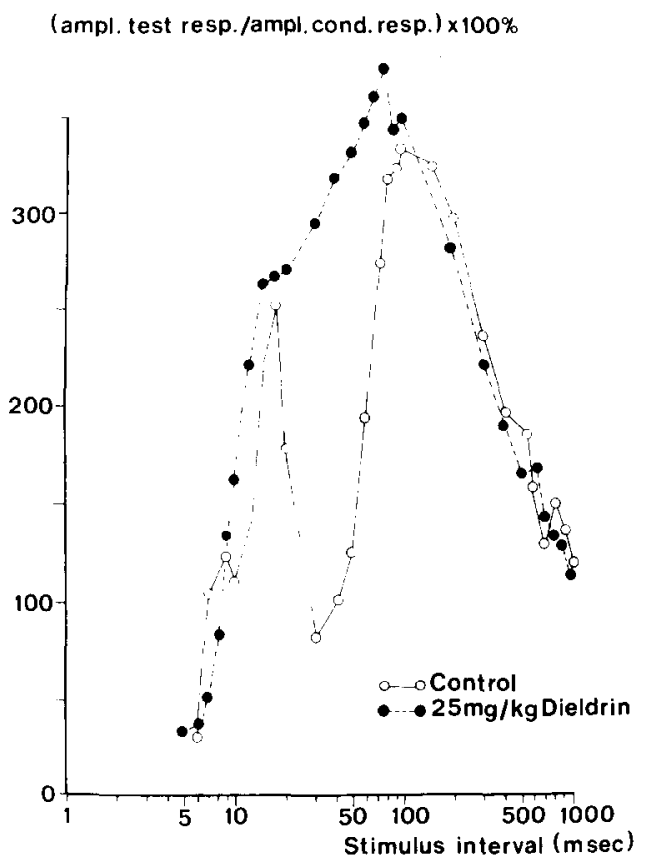

Fig. 3. Effects of dieldrin in vivo on facilitation and inhibition of DR-VRP evoked by two successive orthodromic stimuli to the same segment. Typical facilitation curve of the DR-VRP in a control preparation (continuous line) and in a spinal cord from an animal treated with $35 \mathrm{mg} / \mathrm{kg}$ dieldrin in vivo (dashed line). The interval between conditioning and test stimulus was varied from $5 \mathrm{msec}$ to $1 \mathrm{sec}$. Facilitation was expressed as the ratio between the amplitude of the conditioning response and the amplitude of the test response $\times 100 \%$. Each point presents the mean value of 6 successive measurements at each interval.

ments only a depressive action was observed. In general, depressive effects predominated after prolonged exposure ( $>30 \mathrm{~min})$, but no correlation could be established between concentration and effects of aldrin-transdiol. The results presented below are based on more than 20 different experiments.

\subsubsection{Excitatory effects}

In most preparations bathed in Ringer solution small $(0.1-0.2 \mathrm{mV})$ ventral root potentials, separated by irregular intervals, were recorded in the absence of stimulation (fig. 4A). Application of aldrin-transdiol caused a gradual increase in the frequency of these spontaneous

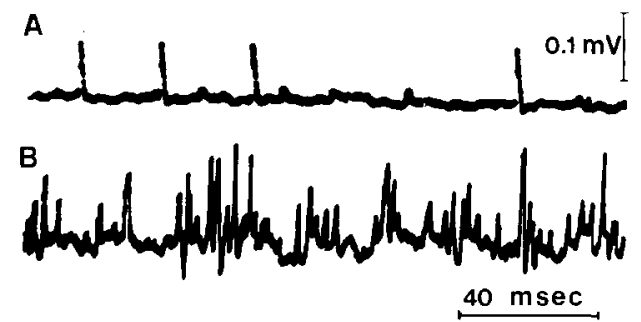

Fig. 4. Effects of aldrin-transdiol on spontaneous ventral root activity. Spontaneous ventral root activity before $(\mathrm{A})$ and $30 \mathrm{~min}$ after application of $2.5 \times 10^{-5}$ $M$ aldrin-transdiol (B).

ventral root potentials, which reached a maximum after 10-30 min of exposure (fig. 4B). High frequency bursts of spontaneous discharges were often noticed at that time. After prolonged exposure the spontaneous activity of the ventral root gradually diminished and finally disappeared.

In a number of preparations it was possible to demonstrate distinct excitatory effects of aldrin-transdiol on the DR-VRP. In some cases both amplitude and duration of the slow synaptic potentials were greatly enhanced, whereas

A

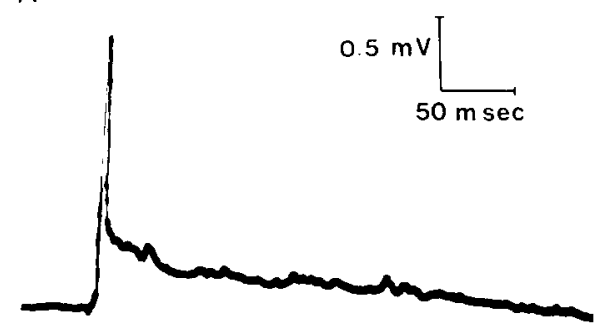

B

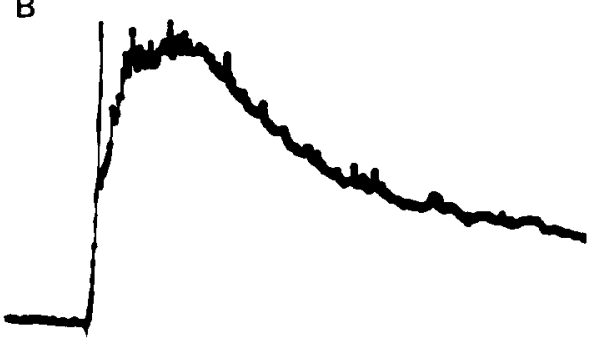

Fig. 5. Excitatory effects of aldrin-transdiol on the DR-VRP. (A) DR-VRP before and (B) 25 min after the application of $2.5 \times 10^{-5} \mathrm{M}$ aldrin-transdiol. 
the synchronized spike discharge was hardly affected (fig. 5). In other experiments the increase of the polysynaptic activity was less pronounced (fig. 8A,C). In a few cases only, there occurred a slight increase in amplitude of the synchronized reflex discharge. After prolonged exposure ( $>30 \mathrm{~min}$ ) these excitatory effects gradually decreased and were followed by a progressive depression of spinal transmission as will be described in the next paragraph.

In contrast to the ventral root the dorsal root is normally silent and only in a few control experiments were spontaneous dorsal root potentials observed. Aldrin-transdiol invariably induced a marked increase in spontaneous dorsal root activity as is illustrated in fig. 6. This effect was also transient and in the end all spontaneous dorsal root, potentials disappeared.

No augmentation on the VR-DRP or the DR-DRP was observed on application of aldrintransdiol.

\subsubsection{Depressant effects}

Fig. 7 demonstrates the depressant action of
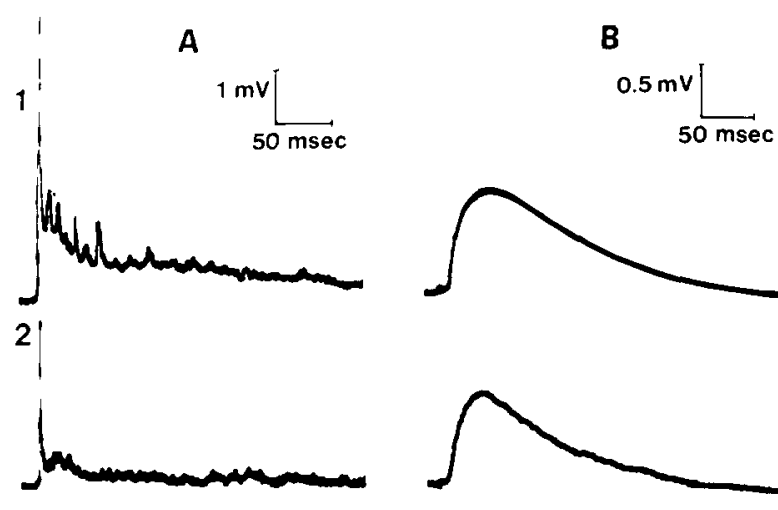

3

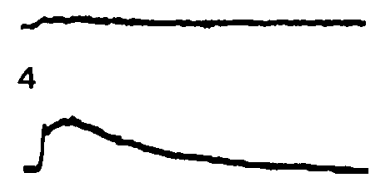

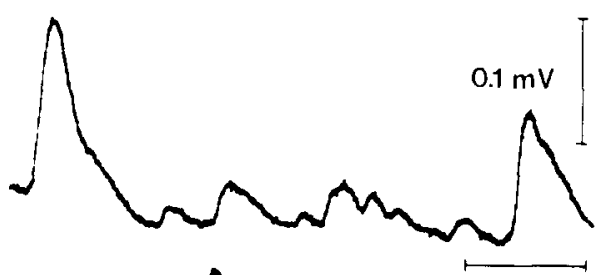
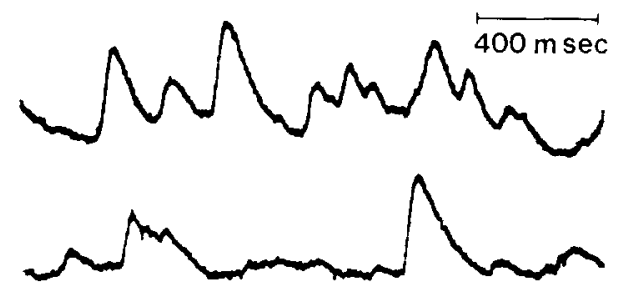

Fig. 6. Effects of aldrin-transdiol on spontaneous dorsal root activity. Spontaneous activity of the dorsal root $40 \mathrm{~min}$ after application of $5 \times 10^{-5} \mathrm{M}$ aldrin-transdiol. Before the addition of aldrin-transdiol to the perfusion fluid no spontaneous activity was recorded.

aldrin-transdiol on spinal root responses. In this experiment no initial potentiation of the DRVRP occurred. After 25 min of treatment with $2.5 \times 10^{-5} \mathrm{M}$ aldrin-transdiol both the monosynaptic and the polysynaptic components of
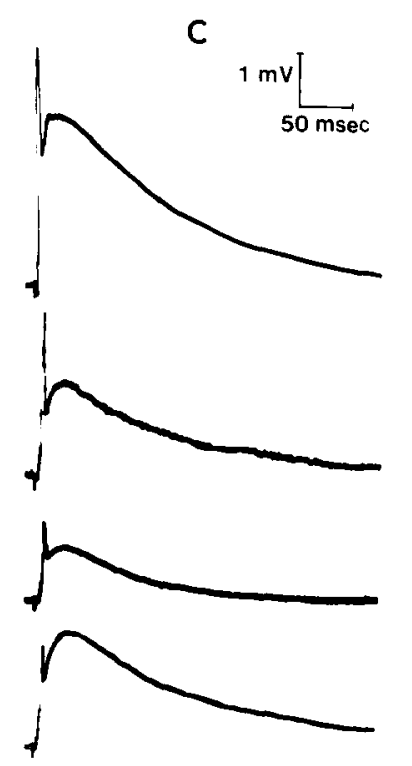

Fig. 7. Depressant effects of aldrin-transdiol on DR-VRP (A), VR-DRP (B) and DR-DRP (C). Root responses were recorded before (1) and at $25 \mathrm{~min}(2)$ and $35 \mathrm{~min}$ (3) after application of $2.5 \times 10^{-5} \mathrm{M}$ aldrin-transdiol, and after washing with normal Ringer solution for $25 \mathrm{~min}(4)$. 
the DR-VRP were effectively suppressed (fig. $7 \mathrm{~A}_{2}$ ). At the same time the amplitude of the VR-DRP (fig. $7 \mathrm{~B}_{2}$ ) was hardly affected, while the DR-DRP (fig. $7 \mathrm{C}_{2}$ ) was reduced too. The DR-VRP, but not the VR-DRP and the DRDRP, was almost completely blocked after 35 min of exposure to aldrin-transdiol (fig. $7 \mathrm{~A}_{3}, \mathrm{~B}_{3}, \mathrm{C}_{3}$ ). The lower tracing of fig. 7 shows that the suppressive effects of aldrin-transdiol could be partly reversed by washing the preparation for 25 min with normal Ringer solution. In general, all root responses were completely abolished when the application of aldrin-transdiol was continued for more than $50 \mathrm{~min}$. The DR-VRP was usually more sensitive to the blocking action of aldrin-transdiol than were the VR-DRP and the DR-DRP.

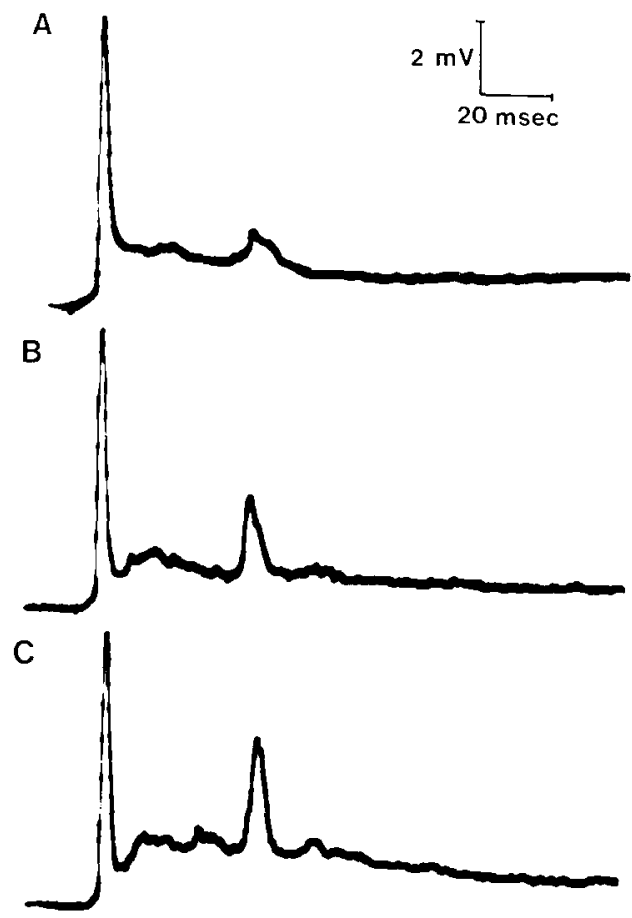

Fig. 8. Effects of aldrin-transdiol on orthodromic inhibition of the DR-VRP. DR-VRP evoked by two successive stimuli separated by an interval of $40 \mathrm{msec}$ before (A), $6 \mathrm{~min}(\mathrm{~B})$ and $13 \mathrm{~min}$ (C) after application of $2.5 \times 10^{-5} \mathrm{M}$ aldrin-transdiol. Inhibition of the second response was gradually reduced by aldrintransdiol.

\section{2.3. Inhibition of the DR-VRP}

It was shown in section 3.1.2. that the synchronized reflex discharge of the DR-VRP can be inhibited when the test stimulus is preceded, within certain time limits, by a conditioning stimulus to the same dorsal root. This type of inhibition, which is supposed to be of postsynaptic origin (Holemans and Meij, 1968), was markedly diminished in spinal cords from dieldrin-treated animals. Fig. 8 illustrates the effect of aldrin-tran. : iol on this type of inhibition. This figure shows the paired DRVRP at a stimulus interval of $40 \mathrm{msec}$ before (A), $6 \mathrm{~min}$ after (B), and $13 \mathrm{~min}$ after (C) exposure to $2.5 \times 10^{-5} \mathrm{M}$ aldrin-transdiol. It is clear that aldrin-transdiol produced a progressive reduction of this type of inhibition. In

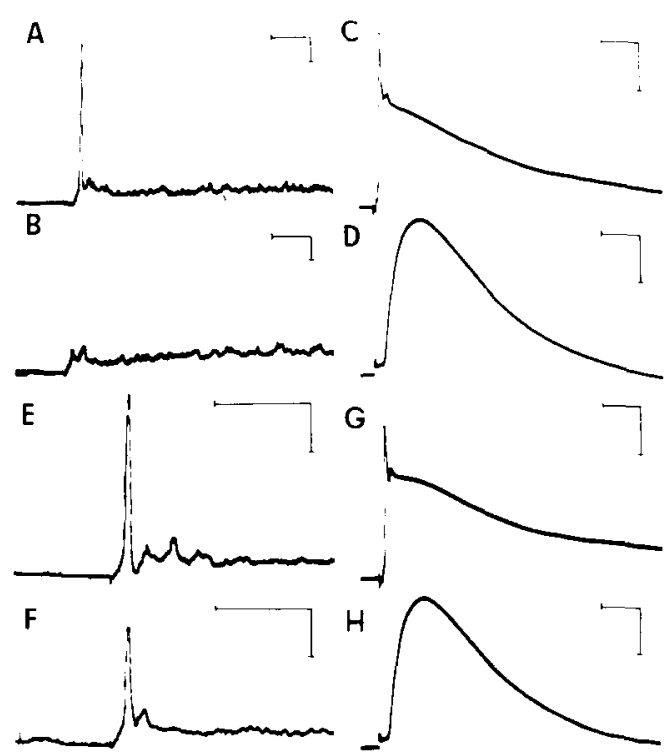

Fig. 9. Effects of aldrin-transdiol on antidromic inhibition of the DR-VRP (left column) and on DR-DRP and VR-DRP (right column). (A)-(D) before and (E)-(H) 45 min after application of $2.5 \times 10^{-5} \mathrm{M}$ aldrin-transdiol. (A) and (E) DR-VRP evoked by a single supramaximal stimulus; (B) and (F) the same response $40 \mathrm{msec}$ after a conditioning stimulation to the adjacent ventral root; $(C)$ and $(G) D R-D R P$ and (D) and (H) VR-DRP before and after application of aldrin-transdiol respectively. Vertical calibration (A) - (C) and (E)-(G) $2 \mathrm{mV}$; (D) and (H) $0.5 \mathrm{mV}$. Horizontal calibration $40 \mathrm{msec}$ in all records. 
other experiments this inhibition was eventually completely lost. The maximum facilitation as measured by means of paired orthodromic dorsal root stimulation was not seriously affected by aldrin-transdiol.

The synchronized reflex discharge can also be inhibited by an antidromically elicited VRDRP. This type of inhibition has been postulated to be presynaptic in origin (Grinnell, 1966; Holemans and Meij, 1968). This type of inhibition was also reduced by aldrin-transdiol as is illustrated in fig. 9. Fig. 9A shows a normal control DR-VRP. In fig. $9 \mathrm{~B}$ this potential is preceded at $40 \mathrm{msec}$ by an antidromical ventral root stimulation to the same segment; the synchronized reflex discharge is now completely inhibited. After treatment with aldrin-transdiol there was a marked reduction in this type of inhibition (fig. 9E,F). Fig. 9 also shows that after the same period of treatment with aldrintransdiol the DR-DRP was only slightly suppressed (fig. 9C,G), while the VR-DRP was not affected at all (fig. 9D,H).

\section{Discussion}

The inability of the insecticide dieldrin to affect the isolated spinal cord in vitro as compared with the marked effects of its metabolite aldrin-transdiol confirms previous observations in frog motor end-plate (Akkermans et al., $1974 a, b)$ and squid giant axon (Van den Bercken and Narahashi, 1974). In both these cases, as well as in the present study, aldrin-transdiol was shown to be very active, whereas dieldrin, even in higher concentrations and after longer exposure did not produce any significant effect. These results are in line with the hypothesis that dieldrin must first be converted to aldrin-transdiol, and possibly other metabolites, before it can exert its neurotoxic action.

However, in the present study, effects of dieldrin could be observed when the insecticide was injected into the living animal $2-8 \mathrm{hr}$ prior to removal of the spinal cord. This would indicate that Xenopus can convert dieldrin to aldrin-transdiol, as has been reported for sever- al species of both insects and mammals (Korte and Arent, 1965; Matthews and Matsumura, 1969; Feil et al., 1970; Baldwin et al., 1972; Tomlin, 1968; Matsumura, 1972). Preliminary experiments by means of gas chromatographic analysis (L.M.A. Akkermans and A. Musch, unpublished results) have shown in fact, that after injection of dieldrin, aldrin-transdiol could be detected in the water in which the animal was kept. Besides, hexachlorohexahydromethanoindene-dicarboxylic acid (aldrinderived dicarboxylic acid) one of the final products of the metabolic pathway of dieldrin (Baldwin et al., 1972) was detected in the surrounding water after injection of aldrintransdiol.

Although the experiments with application of dieldrin in vivo suffer from the lack of adequate control observations in the same preparation, a marked excitatory effect on polysynaptic reflex activity was observed in some cases. Most interesting, however, is the lack of depression of facilitation of the DRVRP without a significant effect on the facilitation itself. It may be inferred from the work of Holemans and Meij (1968) that this depression of facilitation is due to postsynaptic orthodromic inhibition of the motoneurons. Thus the present results suggest that after dieldrin poisoning in vivo postsynaptic inhibition becomes markedly reduced.

Although no detailed facilitation curves were constructed there was clear proof that aldrin-transdiol also causes a reduction of orthodromic inhibition, identical to that observed after dieldrin poisoning. Furthermore, aldrin-transdiol produced a marked reduction of antidromic inhibition. The reduction of this type of inhibition, however, already occurred before a significant change in size and time course of the dorsal root potentials was noticed. This is rather unexpected, since it has been postulated that antidromic inhibition is presynaptic in origin and results from primary afferent depolarization which in turn is respon. sible for the dorsal root potentials (Eccles, 1964; Grinnell, 1966; Holemans and Meij, 1968; Schmidt, 1971). A reduction of presyn- 
aptic antidromic inhibition without a concomitant decrease of dorsal root potentials has also been reported for diphenylthiohydantoin (Raines et al., 1971).

Aldrin-transdiol exerted distinct excitatory effects as manifested by an enhancement of polysynaptic reflex activity and the marked increase in spontaneous activity of both the ventral and dorsal root. In addition aldrintransdiol produced a strong depression of spinal excitability. These results are in keeping with previous observations with the motor end-plate (Akkermans et al., 1974a,b). In this case aldrin-transdiol also caused an initial transient increase in synaptic transmission followed by a progressive depression and eventually a complete blockade. The transient increase in synaptic transmission was shown to be due to a temporary increase in quantal content, whereas the subsequent depression was the result of an inhibition of transmitter release in conjunction with a reduction of the chemical sensitivity of the postsynaptic membrane. It seems reasonable to assume that similar mechanisms are responsible for the action of aldrin-transdiol on spinal synaptic transmission as observed in the present study.

The effects of aldrin-transdiol described here, most notably the reduction of spinal inhibition, are generally associated with convulsant activity. It is well established, for instance, that the convulsant properties of strychnine can be explained by a specific depressant action on postsynaptic inhibition (Curtis, 1963; Eccles, 1964). Two other wellknown convulsants, picrotoxin and bicuculline, have been shown to block presynaptic inhibition (Eccles et al., 1963; Curtis, 1963; Schmidt, 1963; Grinnell, 1966; Davidoff, 1972).

Recently it has been suggested that there exists a close similarity between the actions of dieldrin and pentylenetetrazol in the cat CNS (Joy, 1973; 1974). Studies of the action of pentylenetetrazol on the spinal cord have failed to demonstrate a significant effect on either postsynaptic or presynaptic inhibition (Lewin and Esplin, 1961; Eccles et al., 1963) and so far no adequate explanation for its convulsive properties has been put forward (Esplin and Zablocka-Esplin, 1969). On the other hand the present results indicate that dieldrin in vivo and aldrin-transdiol in vitro suppress spinal inhibitory mechanisms.

\section{Acknowledgement}

We are grateful to Prof. Dr. H. van Genderen for his interest in this study, Mr. J.M. van der Zalm for construction and maintenance of electronic equipment and Miss $\mathrm{H}$. de Wilde for valuable cooperation. We are indebted to Shell Research Ltd., Tunstall Laboratory, Kent for the gift of aldrin-transdiol. This work was sponsored by the Foundation for Medical Research, FUNGO, and by the Shell Corporation.

\section{References}

Akkermans, L.M.A., J. Van den Bercken, J.M. Van der Zalm and H.W.M. Van Straaten, 1974a, Effects of dieldrin (HEOD) and some of its metabolites on synaptic transmission in the frog motor end-plate, Pest. Biochem. Physiol. 4, 313.

Akkermans, L.M.A., J. Van den Bercken and J.M. Van der Zalm, 1975, Effects of aldrin-transdiol on neuromuscular facilitation and depression, European J. Pharmacol. 31, 166.

Baldwin, M.K., J. Robinson and D.V. Parke, 1972, A comparison of the metabolism of HEOD (dieldrin) in the CF1 mouse with that in the CFE rat, Food Cosmet. Toxicol. 10, 333.

Bann, J.M., T.J. DeCino, N.W. Earle and Y.P. Sun, 1965, The fate of aldrin and dieldrin in the animal body, J. Agr. Food Chem. 4, 937.

Barron, D.H. and B.H.C. Matthews, 1938, The interpretation of potential changes in the spinal cord, J. Physiol. 92, 276.

Bercken, J. van den and T. Narahashi, 1974, Effects of aldrin-transdiol - a metabolite of the insecticide dieldrin - on nerve membrane, European J. Pharmacol. 27, 255.

Brooks, G.T., 1960, Mechanisms of resistance of the adult housefly (Musca domestica) to 'cyclodiene' insecticides, Nature 186, 96.

Curtis, D.R., 1963, The pharmacology of central and peripheral inhibition, Pharmacol. Rev. 15, 333.

Davidoff, R.A., 1972, The effects of bicuculline on the isolated spinal cord of the frog, Exp. Neurol. $35,179$.

Davidoff, R.A., 1973, Alcohol and presynaptic inhibi- 
tion in an isolated spinal cord preparation, Arch. Neurol. 28, 60 .

Eccles, J.C., R. Schmidt and W.D. Willis, 1963, Pharmacological studies on presynaptic inhibition, J. Physiol. 168, 500.

Eccles, J.C., 1964, The Physiology of Synapses (Springer-Verlag, Berlin).

Esplin, D.W. and B. Zablocka-Esplin, 1969, Mechanisms of action of convulsants, in: Basic Mechanisms of the Epilepsies, eds. H.H. Jaspar, A.A. Ward and A. Pope (Little, Brown and Company, Boston) p. 167.

Feil, V.J., R.D. Hedde, R.G. Zaylskie and C.H. Zachrison, 1970 , Dieldrin- ${ }^{14} \mathrm{C}$ metabolism in sheep. Identification of trans-6,7-dihydroxy-dihydroaldrin and 9-(syn-epoxy) hydroxy-1,2,3,4,10,10hexachloro - 6,7 -expoxy $-1,4,4 \mathrm{a}, 5,6,7,8,8 \mathrm{a}$-octahydro-1,4-endo-5,8-exo-dimethanonaphthalene, J. Agr. Food Chem. 18, 120.

Giannotti, O., R.L. Metcalf and R.B. March, 1956, The mode of action of aldrin and dieldrin in Periplaneta americana (L.), Ann. Entomol. Soc. Amer. $49,588$.

Gowdey, C.W., A.R. Graham, J.J. Seguin, G.W. Stavraky and R.A. Waud, 1952, A study of the pharmacological properties of the insecticide aldrin, Can. J. Med. Sci. 30, 520.

Gowdey, C.W., A.R. Graham, J.J. Seguin and G.W. Stavraky, 1954, The pharmacological properties of the insecticide dieldrin, Can. J. Biochem. Physiol. 32,498 .

Gowdey, C.W. and G.W. Stavraky, 1955, A study of the autonomic manifestation seen in acute aldrin and dieldrin poisoning, Can. J, Biochem. Physiol. 33,272 .

Grinnell, A.D., 1966, A study of the interaction between motoneurones in the frog spinal cord, J. Physiol. 182, 612.

Hobson, B.M. and B.G. Townsed, 1964, The anaesthetic action of diethyl ether, ethyl carbamate and tricaine methanesulfonate upon Xenopus laevis, in: Small Animal Anaesthesia, ed. O. GrahamJones (Pergamon Press, Oxford) p. 47.

Holemans, K.C., H.S. Meij and B.J. Meyer, 1966, The existence of a monosynaptic reflex arc in the spinal cord of the frog, Exptl. Neurol. 14, 175.

Holemans, K.C., H.S. Meij, B.J. Meyer and J.M. Loots, 1967, The use of the South African frog (Xenopus laevis) in the study of the spinal reflex physiology, Onderstepoort J. Vet. Res. 34, 619.
Holemans, K.C. and H.S. Meij, 1968, An analysis of some inhibitory mechanisms in the spinal cord of the frog (Xenopus laevis), Pflügers Arch. 303, 287.

Joy, R.M., 1973, Electrical correlations of preconvulsive and convulsive doses of chlorinated hydrocarbon insecticides in the CNS, Neuropharmacol. 12, 63.

Joy, R.M., 1974, Alterations of sensory and motorevoked responses by dieldrin, Neuropharmacol. 13,93 .

Korte, F. and H. Arent, 1965, Metabolism of insecticides. IX (1). Isolation and identification of dieldrin metabolites from urine of rabbits after oral administration of dieldrin- ${ }^{14} \mathrm{C}$, Life Sci. 4, 2017.

Lewin, J. and D.W. Esplin, 1961, Analysis of the spinal excitatory action of pentylenetetrazol, J. Pharmacol. Exptl. Therap. 132, 245.

Matsumura, F., 1972, Metabolism of insecticides in microorganisms and insects, in: Environmental Quality and Safety, Vol. 1, eds. F. Coulston and F. Korte (George Thieme Verlag, Stuttgart and Academic Press, New York) p. 96.

Matthews, H.B. and F. Matsumura, 1969, Metabolic fate of dieldrin in the rat, J. Agr. Food Chem. 17, 845.

Narahashi, T., 1971, Effects of insecticides on excitable tissues, in: Advances in Insect Physiology, Vol. 8, eds. J.W.L. Beament, J.E. Treherne and V.B. Wigglesworth (Academic Press, London and New York) p. 1.

Natoff, I.L. and B. Reiff, 1967, The effects of dieldrin (HEOD) on chronaxie and convulsion thresholds in rats and mice, Brit. J. Pharmacol. Chemotherap. 31, 197.

Raines, A., Y.J. Sohn and B. Levitt, 1971, Spinal excitatory and depressant effects of sodium diphenylthiohydantoinate, J. Pharmacol. Exptl. Therap. 177, 350 .

Schmidt, R.F., 1963, Pharmacological studies on the primary afferent depolarization of the toad spinal cord. Pflügers Arch. 277, 325.

Schmidt, R.F., 1971, Presynaptic inhibition in the vertebrate central nervous system, Ergeb. Physiol. Biol. Chem. Exp. Pharmacol. 63, 20.

Tomlin, A.D., 1968, Trans-aldrin glycol as a metabolite of dieldrin in larvae of the southern house mosquito, J. Econ. Entomol. 61, 855.

Wang, C.M., T. Narahashi and Y. Yamada, 1971, The neurotoxic action of dieldrin and its derivates in the cockroach, Pest. Biochem. Physiol. 1, 84. 